\title{
Undernutrition and Associated Factors among Adult Tuberculosis Patients in Hossana Town Public Health Facilities, Southern Ethiopia
}

\section{Tarekegn Geberemeskel $^{1}$, Demelash Woldeyohannes ${ }^{2^{\star}}$ and Meaza Demisie ${ }^{3}$}

${ }^{1}$ SEUHP, Southern Program, Hawassa, Ethiopia

${ }^{2}$ Department of Nursing, College of Medicine and Health Science, Madda Walabu University, Bale Goba, Ethiopia

${ }^{3}$ Department of Public Health, Addis Continental Institute of Public Health, Addis Ababa, Ethiopia

*Corresponding author: Woldeyohannes D, Department of Nursing, College of Medicine and Health Science, Madda Walabu University, Bale Goba, Ethiopia, Tel: +251912097351; E-mail: woldemel@gmail.com

Received date: October 29, 2017; Accepted date: December 28, 2017; Published date: January 08, 2018

Copyright: (c) 2018 Woldeyohannes D, et al. This is an open-access article distributed under the terms of the Creative Commons Attribution License, which permits unrestricted use, distribution, and reproduction in any medium, provided the original author and source are credited.

\begin{abstract}
Background: Undernutrition and tuberculosis (TB) are interconnected in a complex relationship. There is a high prevalence of undernutrition among adult tuberculosis patients worldwide, specifically in developing countries including Ethiopia. Tuberculosis patients are more likely to be wasted or have a lower body mass index than the healthy person. Tuberculosis causes undernutrition through raised metabolic demands, by decreasing nutritional intake and by decreasing necessary immune functions. Implementation of WHO recommended services for TB patients are very week, so this study will fill these gaps.
\end{abstract}

Objective: To assess the magnitude of undernutrition and associated factors among tuberculosis patients at Hossana Town public health facilities.

Method: Institution based cross-sectional study was conducted from November 2015-March 2016 in Hossana Town public health facilities. A total of 247 TB patients were considered for the study. Consecutive study participants were interviewed until the required sample size was reached for each public health facility. Data were entered to SPSS version 20 for statistical analysis. Descriptive statistic, Binary logistic regression was done by using bivariate and multivariate analysis to identify factors associated with undernutrition among TB patients.

Result: The magnitude of undernutrition among adult TB patients was $38.90 \%$. Duration of cough or other TB symptoms before diagnosis of TB ( $A O R=2.27 ; 95 \% \mathrm{Cl}=1.00,5.12)$, family size ( $\mathrm{AOR}=2.98 ; 95 \% \mathrm{Cl}=1.53,5.83)$, and HIV co infection (AOR=5.06; $95 \% \mathrm{Cl}=2.00,12.78$ ) were the factors associated with undernutrition.

Conclusion: The magnitude of undernutrition among adult tuberculosis patients was high. Early screening and diagnosis tuberculosis as well as Nutritional status should be part of the routine care for all adult TB patients. In addition, attention should be given to TB-HIV co infected patients.

Keywords: Tuberculosis; Undernutrition; Associated factors

\section{Introduction}

Tuberculosis and undernutrition are inter linked in a complex relationship. Undernutrition is highly prevalent among people infected with $\mathrm{TB}$ and undernutrition is the risk factor for progression of latent TB to active TB. Undernutrition is a predictor of increased risk of death and TB relapse among TB infected patients [1]. Tuberculosis patients have decreased in appetite, has decreased in nutrient intake, micro nutrient malabsorption, and changed metabolism. These problems lead to wasting. Both protein-energy malnutrition (PEM) and micronutrients deficiencies increase risk death among TB patients. Undernourished TB patients have delayed recovery and higher mortality rates than well-nourished TB patients [2]. Tuberculosis (TB) causes undernutrition through raised metabolic demands and decline in nutrition intake, and nutritional deficiencies may exacerbate the TB disease, or it takes longer recovery by decreasing necessary immune functions [3]. Malnutrition is recurrently detected in tuberculosis patients [4].

Hard to determine exactly what the nutritional status of patients with active TB was earlier the onset of the disease, making it difficult to fix whether malnutrition directed to the advancement of the disease or whether active TB directed to malnutrition. Number studies described that patients with active TB are more likely to be wasted or have a lower body mass index than the healthy person [5].

The systemic literature review concluded that there was a long linear inverse relationship between $\mathrm{TB}$ incidence and BMI, within the BMI range $18.5-30 \mathrm{~kg} / \mathrm{m}^{2}$. The average slope gave a reduction in $\mathrm{TB}$ incidence of $13.8 \%$ [ $95 \%$ CI 13.4-14.2] per unit increase in BMI. The dose-response relationship was less certain at BMI $<18.5$ and 430 $\mathrm{kg} / \mathrm{m}^{2}$ [6]. Undernutrition problem among TB patients depends on their treatment category, BMI progressively increased as the treatment duration increased from start up to completion [7]. 
A study conducted in Indonesia shows that $87 \%$ of TB patients had malnutrition compared to healthy persons. The mean body mass index (BMI), family history of TB, family size and employment status are the associated factors with undernutrition of TB patients [8].

Study conducted in Ghana shows undernutrition among TB patients was significantly associated with marital status, monthly income, educational status and family size at the time of starting TB treatment. Two months after initiating the TB treatment change in body mass index was significantly associated to age, marital status, employment status, and educational status [9].

A study conducted in Uganda and Malawi reveals that there is higher undernutrition among adult TB patients. Moreover, another study conducted in Uganda showed that undernutrition among adult TB patients was $62 \%[10,11]$.

As studies conducted in Ethiopia (Gonder and Addis Ababa) shows that there was higher prevalence of undernutrition among Adult TB patients $65 \%$ and $39.7 \%[12,13]$.

WHO recommended services for $\mathrm{TB}$ patients are nutrition assessment and counseling, management of malnutrition and supplementation of micronutrients. However, implementation of these services is very week and limitations of researches conducted on undernutrition and associated factors among adult tuberculosis patients in Hossana town hindered the provision of appropriate services as recommended by WHO. So, the aim of this study was to fill these gaps. Moreover, the findings of this study will be used for evidence-based intervention in the study area. And it will also provide information for health planners, managers and researchers.

\section{Methodology}

\section{Study area}

Hossana Town is the capital town of Hadiya zone, which is located $232 \mathrm{~km}$ far from Addis Ababa, the capital city of Ethiopia, and $194 \mathrm{~km}$ far from the regional city, Hawassa [14]. Hosanna Town has divided in to three sub cities and eight administrative Kebeles. According to the 2015/16 G.C data, the Town has a total population of 100501 from which 50984 (50.73\%) were females. The Town had one zonal public Hospital (Nigist Eleni Mohamed Memorial Hospital) and three public health centers (Hossana Health Center, Lichamba Health Center and Bobicho Health Center). All these public Hospitals has currently started TB treatment services.

\section{Study design and study period}

The institution based cross-sectional study was conducted from November 2015-March 2016.

\section{Source and study population}

All adult TB patients currently recorded and on TB treatment care in Hossana town public health facilities were considered as source population. Tuberculosis patients who were visiting the public health facility during the data collection period were study population.

\section{Inclusion and exclusion criteria}

Adult TB patients age $\geq 18$ in public health facilities and those who were visiting public Health facility during study period irrespective of their sex were included in the study whereas TB patients with a serious mental health problem were excluded from the study.

\section{Sample size determination}

Single population proportion formula was used to determine the sample size. The following assumptions were considered. The prevalence of malnutrition among Tuberculosis patients $39.7 \%$ which gives a maximum sample size after checking for different factors from different literatures [13], 95\% confidence interval and 5\% margin of error.

$$
\mathrm{n}=\mathrm{z}_{\frac{\alpha}{2}}^{2} * \frac{P(1-P)}{d^{2}}=(1.96)^{2} * 0.39(0.61) / 0.0025=366 .
$$

Then, the correction factor formula was used to determine final sample size because the source population was less than 10,000.

$\mathrm{nf}=\mathrm{n} /(1+\mathrm{n} / \mathrm{N})=366 / 1+366 / 596=224$ and the final sample size was 247 after considering a $10 \%$ non-response rate.

\section{Sampling procedures}

All public health facilities in Hossana town were considered for the study (Nigist Eleni Mohamed Memorial Hospital, Hossana Health Center, Lichamba Health Center and Bobicho Health Center). The sample size for each public health facilities was calculated based on the population proportion to size TB patient currently enrolled for each public health facility. Study participants were consecutively interviewed until the required sample size reached for each public health facility.

\section{Data collection tools and procedures}

A structured questionnaire was adopted after reviewing different scientific literatures on the area of undernutrition and associated factors among TB patients. The adopted questionnaire was translated into Amharic and back to English to check its consistency.

Public Health facilities record were used to collect information on basic demographic data, type of Pulmonary TB, the length of symptom before the diagnosis of Tuberculosis, and length of treatment after diagnosis of tuberculosis. Information like monthly income and number of family size was collected by interviewing study participants.

\section{Measurement}

Weight was measured at the time of data collection to the nearest $\pm 100 \mathrm{~g}$ precision on a digital standing scale. Weight was measured with minimal or light clothing on and calibration to zero continuously conducted after each measurement. Known weight measurement for checking the instrument was carried out daily before any measurement had started. The same weight measurement instruments were used and calibrated at each morning to ensure validity of the results. Height of the patients was measured while standing erect without shoes with a stadiometer using standard procedures. Both height and weight were recorded with two decimal places. Body mass index (BMI in $\mathrm{kg} / \mathrm{m}^{2}$ ) was calculated and classified into categories as recommended by WHO.

\section{Data quality management}

Data collectors and supervisor were deployed based on educational status and experience in a TB clinic. Two days training were given on 
Citation: Geberemeskel T, Woldeyohannes D, Demisie M (2018) Undernutrition and Associated Factors among Adult Tuberculosis Patients in Hossana Town Public Health Facilities, Southern Ethiopia. J Trop Dis 6: 253. doi:10.4172/2329-891X.1000253

Page 3 of 7

data collection tools and procedure. Standardization for weight and height measurement during intra and inter-data collection was conducted. The questionnaire was pre-tested in two public health facilities out of the main study area and necessary corrections were made. Crosschecking for completeness during data collection on daily basis were conducted. Moreover, data cleaning and checking were done before analysis and a unique code number labeled for each individual questionnaire that helped to found missed value and to retrieve back during analysis.

\section{Data analysis}

Data were entered into SPSS version 20 for descriptive and logistic regression analysis. Bivariate and multivariate analysis was used to identify factors associated with undernutrition among TB patients. Variables with $\mathrm{p} \leq 0.2$ in the bivariate logistic regression analysis were entered into multivariate logistic regression analysis. Variables in multivariate logistic regression analysis with $\mathrm{P}$ value $\leq 0.05$ was considered as significantly associated factors with outcome variable.

\section{Operational definitions}

Undernutrition: A person with $\mathrm{BMI}<18.5 \mathrm{~kg} / \mathrm{m}^{2}$ were considered as undernutrition.

Body mass index (BMI): BMI is defined as weight of the individual divided by the square of the same individual height in meter and classified as BMI $<16.0 \mathrm{~kg} / \mathrm{m}^{2}$ (Sever Undernutrition), BMI $16.0 \mathrm{~kg} /$ $\mathrm{m}^{2}-16.99 \mathrm{~kg} / \mathrm{m}^{2}$ (Moderate undernutrition), BMI $17.0 \mathrm{~kg} / \mathrm{m}^{2}-18.49$ $\mathrm{kg} / \mathrm{m}^{2}$ (Mild undernutrition), BMI $18.5 \mathrm{~kg} / \mathrm{m}^{2}-24.99 \mathrm{~kg} / \mathrm{m}^{2}$ (Normal weight), BMI $25.0 \mathrm{~kg} / \mathrm{m}^{2}-29.99 \mathrm{~kg} / \mathrm{m}^{2}$ (Overweight) and BMI $\geq 30$ $\mathrm{kg} / \mathrm{m}^{2}$ (Obesity).

Duration of cough or other TB symptom before diagnosis of TB: Length or duration of days lasted with a cough or other TB symptoms like accidental weight loss, night sweats, loss of appetite, and fever before the diagnosis of $\mathrm{TB}$

\section{Ethical Consideration}

Ethically clearance was obtained from Addis Continental Institute of Public Health, Ethical Committee. Ethical committee confirms, the instruments and procedures will not cause any harm on study participants. Permission letter was obtained from Hadiya Zone Health Department, Hossana town administration health office, and respective Public health facilities. Written and oral consent was obtained from each study participants after explaining the purpose of the study. Confidentiality was ensured by not writing their personal identification. The privacy of study participants was ensured. Respondents with a problem of undernutrition were counseled and referred for appropriate nutritional care and support.

\section{Results}

\section{Socio demographic characteristics of study participants}

The mean age of study participants was $32.90( \pm 14.60)$ years. More than half of the study participants were married 140 (57\%) and less than fifty percent of the study participants were single $99(40 \%)$. Half of the study participants were protestants 124 (50\%), 43 (17\%) of study participants had no formal education, and 91 (37\%) of the study participants were unemployed.

Among study participants, 206 (83\%) were living in the urban area and 93 (37\%) had a family size of less than or equal to five and 93 (37\%) of the study participants had the lowest monthly income quintile which was less than 300 ETB (Table 1).

\begin{tabular}{|c|c|c|c|}
\hline Variables & Category & Frequency $(N)=247$ & Percentage (\%) \\
\hline \multirow[t]{4}{*}{ Age } & $<24$ & 84 & 34.0 \\
\hline & $24-30$ & 65 & 26.3 \\
\hline & $31-40$ & 41 & 16.6 \\
\hline & $>40$ & 57 & 23.1 \\
\hline \multirow[t]{2}{*}{ Sex } & Male & 129 & 52.2 \\
\hline & Female & 118 & 47.8 \\
\hline \multirow[t]{4}{*}{ Marital Status } & Married & 140 & 56.7 \\
\hline & Single & 99 & 40.1 \\
\hline & Divorced & 4 & 1.6 \\
\hline & Widowed & 4 & 1.6 \\
\hline \multirow[t]{4}{*}{ Religion } & Protestant & 124 & 50.2 \\
\hline & Orthodox & 86 & 34.8 \\
\hline & Muslim & 33 & 13.4 \\
\hline & Catholic & 4 & 1.6 \\
\hline
\end{tabular}


Citation: Geberemeskel T, Woldeyohannes D, Demisie M (2018) Undernutrition and Associated Factors among Adult Tuberculosis Patients in Hossana Town Public Health Facilities, Southern Ethiopia. J Trop Dis 6: 253. doi:10.4172/2329-891X.1000253

Page 4 of 7

\begin{tabular}{|c|c|c|c|}
\hline \multirow[t]{5}{*}{ Educational Status } & No Formal Education & 43 & 17.4 \\
\hline & Primary (Grade 1-8) & 85 & 34.4 \\
\hline & Secondary (Grade 9-10) & 69 & 27.9 \\
\hline & Preparatory (Grade 11-12) & 28 & 11.3 \\
\hline & Post Preparatory (Grade $12+$ ) & 22 & 8.9 \\
\hline \multirow[t]{5}{*}{ Occupation } & Housewife & 54 & 21.9 \\
\hline & Government Employee & 24 & 9.7 \\
\hline & Farmer & 35 & 14.2 \\
\hline & Merchant & 43 & 17.4 \\
\hline & Unemployed & 91 & 36.8 \\
\hline \multirow[t]{2}{*}{ Residence } & Urban & 206 & 83.4 \\
\hline & Rural & 41 & 15.0 \\
\hline \multirow[t]{2}{*}{ Family Size } & $\leq 5$ & 154 & 62.3 \\
\hline & $>5$ & 93 & 37.7 \\
\hline \multirow[t]{3}{*}{ Income(ETB) } & $<300$ & 93 & 37.7 \\
\hline & $300-1100$ & 92 & 37.2 \\
\hline & $>1100$ & 62 & 25.1 \\
\hline
\end{tabular}

Table 1: Socio-demographic characteristics of study participants at Hossana town public health facilities, Southern Ethiopia, November 2015March 2016.

\section{Health status of the study participants}

Among study participants, 35 (14\%) of them were HIV positives, 30 (12\%) of study participants showed the symptom of a cough or other TB symptoms within less than one month, 172 (69\%) study participants were showed the symptom of a cough or other TB symptoms within one to three months and 45 (18\%) of study participants were showed the symptom of a cough or other TB symptoms after three months before diagnosis of TB.
From study participants, 101 (40\%), 116 (47\%) and 30 (12\%) were smear positive, smear negative and extra pulmonary TB patients respectively. More than ninety percent of study participants were new TB cases $227(92 \%)$. A total of $136(55 \%)$ and 111 (45\%) of the study participants were in the intensive and continuous phase of the treatment respectively (Table 2 ).

\begin{tabular}{|l|c|c|c|}
\hline Variable & Category & Frequency (N=247) & Percentage (\%) \\
\hline \multirow{2}{*}{ Pregnancy Status } & No & 110 & 93.2 \\
\cline { 2 - 4 } & Yes & 8 & 6.8 \\
\hline \multirow{2}{*}{ Lactation Status } & No & 113 & 95.8 \\
\cline { 2 - 4 } & Yes & 5 & 4.2 \\
\hline \multirow{2}{*}{ Co morbidity } & Reactive & 35 & 14.2 \\
\hline Diabetes & Non-Reactive & 212 & 85.8 \\
\cline { 2 - 4 } & & & \\
\hline Chronic Kidney Disease & No & 234 & 94.7 \\
\cline { 2 - 4 } & Yes & 13 & 5.3 \\
\hline
\end{tabular}


Citation: Geberemeskel T, Woldeyohannes D, Demisie M (2018) Undernutrition and Associated Factors among Adult Tuberculosis Patients in Hossana Town Public Health Facilities, Southern Ethiopia. J Trop Dis 6: 253. doi:10.4172/2329-891X.1000253

Page 5 of 7

\begin{tabular}{|c|c|c|c|}
\hline & Yes & 9 & 3.6 \\
\hline \multirow{3}{*}{$\begin{array}{l}\text { Duration of cough or other TB Symptom before } \\
\text { diagnosis of TB }\end{array}$} & Less Than a month & 30 & 12.1 \\
\hline & 1-3 month & 172 & 69.6 \\
\hline & 3 months and above & 45 & 18.2 \\
\hline \multirow[t]{3}{*}{ Type of TB } & Smear + & 101 & 40.9 \\
\hline & Smear - & 116 & 47.0 \\
\hline & EPTB & 30 & 12.1 \\
\hline \multirow[t]{3}{*}{ Form of TB } & New case & 227 & 91.9 \\
\hline & Retreatment Case & 15 & 6.1 \\
\hline & MDR & 5 & 2.0 \\
\hline \multirow[t]{2}{*}{ Anti-TB Rx Status } & Intensive Phase & 136 & 55.1 \\
\hline & Continuous Phase & 111 & 44.9 \\
\hline
\end{tabular}

Table 2: Health status of adult tuberculosis patients at Hossana Town public health facilities, Southern Ethiopia, November 2015-March 2016.

\section{Anthropometric status of the study participants}

The mean height, weight, and BMI of the study participants were $177 \mathrm{~cm}( \pm 0.94), 57 \mathrm{~kg}( \pm 8.97)$ and $19.36 \mathrm{~kg} / \mathrm{m}^{2}( \pm 3.00)$ respectively. Ninety-six study participants had a BMI less than $18.5 \mathrm{~kg} / \mathrm{m}^{2} 96$
(38.9\%) (undernutrition), whereas only one study participant had a BMI greater than or equal to $25 \mathrm{~kg} / \mathrm{m}^{2}$ (overweight). The study participants with weight less or equal to $45 \mathrm{~kg}$ were 21 (8.5\%) (Table 3).

\begin{tabular}{|l|l|l|l|}
\hline \multicolumn{1}{|c|}{ Anthropometric Variable } & Category & Frequency (N) & Percentage (\%) \\
\hline Adult TB patient Height & $>145 \mathrm{~cm}$ & 247 & 100 \\
\hline Adult TB patient weight & $\leq 45 \mathrm{~kg}$ & 21 & 8.5 \\
\cline { 2 - 5 } & $>45 \mathrm{~kg}$ & 226 & 91.5 \\
\hline \multirow{2}{*}{ Nutritional Status } & $<18.5 \mathrm{~kg} / \mathrm{m}^{2}$ (Undernutrition) & 96 & 38.9 \\
\cline { 2 - 4 } & $\begin{array}{l}18.5 \mathrm{~kg} / \mathrm{m}^{2}-24.99 \mathrm{~kg} / \mathrm{m}^{2} \\
(\text { Normal) }\end{array}$ & 150 & 60.7 \\
\cline { 2 - 4 } & $\geq 25 \mathrm{~kg} / \mathrm{m}^{2}$ (Overweight) & 1 & 0.4 \\
\hline
\end{tabular}

Table 3: Anthropometric status of adult tuberculosis patients at Hossana Town public health facilities, Southern Ethiopia, November 2015-March 2016.

\section{Factors associated with undernutrition in adult tuberculosis patients}

Bivariate and multivariate logistic regression analysis was conducted to identify factors associated with undernutrition of Tuberculosis patients. The odd of being undernourished were three times more likely in TB patients who stayed more than 3 months with symptom of a cough or other TB symptoms before diagnosis of TB as compared to TB patients stayed with symptom of a cough or other TB symptom less than 3 months before diagnosis of $\mathrm{TB}(\mathrm{AOR}=2.27 ; 95 \% \mathrm{CI}=1.00,5.12)$.
The odds of being undernourished were three times more likely in TB patient with family size of more than five household members when compared to those who have the small number of household family members ( $\mathrm{AOR}=2.98 ; 95 \% \mathrm{CI}=1.53,5.83)$.

The odds of being undernourished were five times more likely in $\mathrm{TB}$ patient who has HIV positive result when compared to TB patient who has negative HIV test result ( $\mathrm{AOR}=5.06 ; 95 \% \mathrm{CI}=2.00,12.78)$ (Table $4)$.

\begin{tabular}{|l|l|l|l|l|}
\hline \multirow{2}{*}{ Variables } & \multicolumn{2}{|l|}{ Undernutrition } & COR (95\%Cl) & AOR (95\%Cl) \\
\cline { 2 - 4 } & Yes & No & & \\
\hline
\end{tabular}


Page 6 of 7

\begin{tabular}{|c|c|c|c|c|c|c|c|}
\hline \multirow[b]{2}{*}{ Family Size } & \multirow[b]{2}{*}{$\leq 5$} & \multicolumn{2}{|c|}{ No $(\%)$} & \multicolumn{2}{|c|}{ No $(\%)$} & \multirow[b]{2}{*}{$2.53(1.49,4.31)$} & \multirow[b]{2}{*}{$2.98(1.53,5.83)^{\star}$} \\
\hline & & 47 & 30.52 & 107 & 69.48 & & \\
\hline & $>5$ & 49 & 52.69 & 44 & 47.31 & 1.00 & 1.00 \\
\hline \multirow[t]{3}{*}{ Income } & $<300$ & 40 & 43.01 & 53 & 56.99 & $2.36(1.16,4.81)$ & $1.76(0.54,5.74)$ \\
\hline & $300-1100$ & 41 & 44.57 & 51 & 55.43 & $2.52(1.24,5.13)$ & $1.97(0.71,5.48)$ \\
\hline & $>1100$ & 15 & 24.19 & 47 & 75.81 & 1.00 & 1.00 \\
\hline \multirow[t]{2}{*}{ HIV Status } & Reactive & 23 & 65.71 & 12 & 34.29 & $3.65(1.71,7.75)$ & $5.06(2.0,12.78)^{\star}$ \\
\hline & Non-Reactive & 73 & 34.43 & 139 & 65.57 & 1.00 & 1.00 \\
\hline \multirow{3}{*}{$\begin{array}{l}\text { Duration of cough or other } \\
\text { TB Symptom before } \\
\text { diagnosis of TB }\end{array}$} & Less than a month & 4 & 13.33 & 26 & 86.67 & $27.9(8.3,94.2)$ & $0.57(0.15,2.24)$ \\
\hline & 1-3 month & 76 & 44.19 & 96 & 55.81 & $1.43(0.72,2.83)$ & $2.27(1.00,5.12)^{\star}$ \\
\hline & 3 months and above & 16 & 35.56 & 29 & 64.44 & 1.00 & 1.00 \\
\hline \multirow[t]{2}{*}{ Anti-TB treatment status } & Intensive Phase & 64 & 47.06 & 72 & 52.94 & 1.00 & 1.00 \\
\hline & Continuous Phase & 32 & 28.83 & 79 & 71.17 & $2.19(1.29,3.73)$ & $0.56(0.3,1.06)$ \\
\hline
\end{tabular}

Table 4: Factors associated with undernutrition among adult Tuberculosis patients at Hossana town public health facilities, Southern Ethiopia, November 2015-March 2016.

\section{Discussion}

The finding of this study showed that $38.90 \%$ of the study participants were undernourished this finding is in line with a recently conducted study in Addis Ababa [13]. This is might be due to relatively the same quality of service provision, care, and support, including nutritional counseling service for TB patients in Public health facilities. Also, public health facilities in the country follows the same TB program intervention strategy both at community and health facility level. As per the study conducted in Taipei, Taiwan and Peru undernutrition of adult TB patients were lower than the finding of this study $[15,16]$. Whereas, the study conducted in Gonder (Ethiopia), rural India, Uganda, Sekondi-Takoradi (western region of Ghana) and Malawi revealed that higher undernutrition status among adult TB patient than the finding of this study $[9-12,17]$. This difference might be due to a socioeconomic situation, sociocultural situation, lifestyle, feeding pattern difference of the countries and time of the study conducted.

This study revealed that TB patients stayed more than three months with the symptom of a cough or other TB symptoms before diagnosis of TB were more likely to develop undernutrition when compared to patient stayed with the symptom of a cough or other TB symptoms less than three months before diagnosis of TB. This finding might be due to the fact of Tuberculosis suspected patients are more prone to undernutrition and need early detection and referral within three weeks or less than three weeks for diagnosis and treatment including the necessary nutritional support and follow-up [18].

Poor nutritional status reflects the socio-demographic context in which a risk factor for the development of Tuberculosis infection [19]. Studies revealed that overcrowded homes and living in densely populated neighborhoods are conducive for an increased transmission of Tuberculosis bacilli and also could contribute to the development of TB [20-23]. In addition, a study in Ghana [6] and Indonesia [8] revealed that leaving in an extended and large family size were found to be associated with undernutrition among adult TB patients. This fact was in line with the finding of this study in which TB patient with a large number of family size was more likely to develop undernutrition when compared to those who have a small number of household family members [24,25].

A study in Malawi, showed that HIV co-infection with Tuberculosis is known to contribute and worsen the degree of undernutrition among TB patients in which strengthen the finding of the current study. This study revealed that TB patient who has HIV positive result were more likely to develop undernutrition when compared to TB patient who has negative HIV test result which was in line with the finding of the study in Gondar too [12].

\section{Conclusion and Recommendation}

This study revealed that undernutrition status among adult Tuberculosis patients was very high. Duration of a cough or another symptom of TB before diagnosis and treatment of TB, family size, and HIV co-infection were factors associated with undernutrition among adult TB patients. Early screening and diagnosis Tuberculosis as well as Nutritional status should be part of the routine care for all adult TB patients. In addition, attention should be given to TB-HIV co infected patients.

\section{Acknowledgment}

Authors are thankful for all participants for devoting their precious time to take part in this study.

\section{References}

1. WHO (2013) Guideline on Nutritional care and support for patients with Tuberculosis. Geneva.

2. http://www.ncbi.nlm.nih.gov/pmc/articles/PMC2813110/ 
Citation: Geberemeskel T, Woldeyohannes D, Demisie M (2018) Undernutrition and Associated Factors among Adult Tuberculosis Patients in Hossana Town Public Health Facilities, Southern Ethiopia. J Trop Dis 6: 253. doi:10.4172/2329-891X.1000253

Page 7 of 7

3. Sinclair D, Abba K, Grobler L, Sudarsanam TD (2011) Nutritional supplements for people being treated for active Tuberculosis: areviwe, Cochrane Collaboration 2: 11

4. Miyata S, Tanako M, Ihaku D (2013) The prognostic significance of nutritional status using malnutrition universal screening tool in patients with pulmonary Tuberculosis. Miyata et al Nutrition Journal 12: 42.

5. United States agency for international development (2010) Nutrition and Tuberculosis: a review of literature and considerations for TB control program.

6. Lonnroth K, Williams BG, Cegielski P, Dye C (2010) A consistent loglinear relationship between Tuberculosis incidence and body mass index. Int J Epi 39: 149-155.

7. Tungdim MG, Kapoor S (2008) Tuberculosis treatment and nutritional status among the tribales of Northeast india 52: 323-327.

8. Pakasi TA, Karyadi E, Dolmans WMV, Van der Meer JMW, Velden KV (2009) Malnutrition and socio-demographic factors associated with pulmonary Tuberculosis in Timor and Rote Islands, Indonesia. Int J Tuberc Lung Dis 13:755-759.

9. Emmanuel Atsu D (2008) E Evaluation of nutritional status of new Tuberculosis patients at the Effia - Nkwanta regional hospital. Ghana Medical Journal 42(1).

10. Shah S, Whalen C, Kotler DP, Mayanja H, Namale A, et al. (2001) Severity of human immunodeficiency virus infection is associated with decreased phase angle, fat mass and body cell mass in adults with pulmonary Tuberculosis infection in Uganda. J Nutr 131: 2843-2847.

11. Zachariah R, Spielmann MP, Harries AD, Salaniponi FML (2002) Moderate to severe malnutrition in patients with Tuberculosis is a risk factor associated with early death. Trans R Soc Trop Med Hyg 96: 291-294.

12. Kassu A, Yabutani T, Mahmud ZH, Mohammad A, Nguyen N, et al (2006) Alterations in serum levels of trace elements in Tuberculosis and HIV infections. Eur J Clin Nutr 60: 580-586.

13. Dargie B, Tesfaye G and Worku A (2016) Prevalnce and associated factors of undernutrition among adult Tuberculosis patients in some selected public health facilities of Addis Ababa, Ethiopia. BioMed Cen 2: 7.

14. Hadiya zone health department (2015) Sixth months report on plan and performance of activities.

15. Yen YF, Chuang PH, Yen MY, Lin SY, Chuang P, et al. (2016) Association of Body Mass Index With Tuberculosis Mortality. Medicin 95: e2300.
16. Krapp F,Veliz VC, Cornejo E, Gotuzzo E, Seas C, et al. (2008) Body weight gain to predict treatment outcome in in patients with pulmonary Tuberculosis in Peru. Int J Tuberc Lung Dis 12: 1153-1159.

17. Bhargava A, Chatterjee M, Jain Y, Chatterjee B, Kataria A, et al. (2013) Nutritional Status of Adult Patients with Pulmonary Tuberculosis in Rural Central India and Its Association with Mortality. PLOS ONE 8: e77979.

18. Federal democratic republic of Ethiopia ministry of health (2012) Guidelines for clinical and programmatic management of TB, Leprosy and TB/HIV in Ethiopia. Fifth edition. Addis Ababa.

19. Frimpong EH, Lawn SD, Antwi P, Dwemoh B, Afful B, Acheapong JW (1997) HIV infection in Tuberculosis patients in Kumasi. Ghana Med J 31: 850-854.

20. Narain JP, Raviglione MC, Kochi A (1992) HIV Associated Tuberculosis in Developing Countries: Epidemiology and Strategies for Prevention. Tubercle and Lung Disease 73: 311-321.

21. Karyadi E, West CE, Schultink W, Nelwan RHH, Gross R, Amin Z, et al. (2002) A double-blind, placebo controlled study of vitamin A and zinc supplementation in persons with Tuberculosis in Indonesia: effects on clinical response and nutritional status. Am J Clin Utr 75: 720-727.

22. Paton NI, Chua YK, Earnest A, Chee CBE (2004) Randomized controlled trial of nutritional supplementation in patients with newly diagnosed Tuberculosis and wasting. Am J Clin Utr 80: 460-465.

23. Harries AD, Nkhoma WA, Thompson PJ, Nyangulu DS, Wirima JJ (1988) Nutritional status in Malawian patients with pulmonary Tuberculosis and response to chemotherapy. Eur J Clin Nutr 42: 445-450.

24. Wassei MM, Worku AG, Shamil J (2014) Weight gain and associated factors among adult Tuberculosis patients on treatment in Northwest Ethiopia. J Nutr Disorders Ther 2: 143-162.

25. Hossana Town Health Office (2015) Annual plan performance report. 